\title{
Semantic Categories in the Domain of Motion Verbs by Adult Speakers of Danish, German, and Turkish*
}

\author{
Moiken Jessen (Odense, Denmark)
}

\begin{abstract}
Languages differ in the ways they divide the world. This study applies cluster analysis to understand how and why languages differ in the way they express motion events. It further lays out what the parameters of the structure of the semantic space of motion are, based on data collected from participants who were adult speakers of Danish, German, and Turkish. The participants described 37 video clips depicting a large variety of motion events. The results of the study show that the segmentation of the semantic space displays a great deal of variation across all three groups. Turkish differs from German and Danish with respect to the features used to segment the semantic space - namely by using vector orientation. German and Danish differ greatly with respect to (a) how fine-grained the distinctions made are, and (b) how motion verbs with a common Germanic root are distributed across the semantic space. Consequently, this study illustrates that the parameters applied for categorization by speakers are, to some degree, related to typological membership, in relation to Talmy's typological framework for the expression of motion events. Finally, the study shows that the features applied for categorization differ across languages and that typological membership is not necessarily a predictor of elaboration of the motion verb lexicon.
\end{abstract}

\section{$1 \quad$ Introduction}

While one can easily be buried in a kiste in Danish, it would be rather odd to be found six feet under in a Kiste in German. This has to do with the range of these cognate words in their respective languages. While in Danish a kiste relates more to a coffin than to a box, it only covers boxes in German. The motion event that might have led to this unfortunate situation could be described as Er balancierte auf einem Hochseil, conflating the act of walking and keeping the balance in German, whereas He was walking on a tightrope for English relies on the listener's world-knowledge to infer the keeping of the balance.

Different languages offer different means of conveying how motion is expressed; i.e., motion events can be coded by various combinations of lexical items and grammatical morphemes.

\footnotetext{
* I would like to thank Teresa Cadierno, Barbara C. Malt, and the anonymous reviewers of the present article for their insightful and helpful comments. The research reported in this paper is part of the VELUX Foundationfinanced project "Usage-based approaches to second language acquisition." Special thanks are due to Toker Doganoglu for his help with the statistical analysis and Mila Vulchanova for kindly letting us use the videos in this experiment. All remaining errors are mine.
}

Linguistik online 61, 4/13 
Semantic event representation is not solely done in the verb. However, verbs are used to refer to relations between entities and are thus the core of encoding events. Therefore, the aim of the present study is to address the linguistic encoding of motion events with a specific focus on the semantics of motion verbs; i.e., it aims at discovering to what extent and in what respect languages vary in the lexical labels used to express motion events. Cluster analysis can give important insights with respect to the semantic organization of verbs in a certain domain, as shown, e.g., for cutting and breaking verbs (Majid et al. 2007). In combination with an illustration of the verb range, we show in specific terms how languages differ in their lexicalization patterns. Special focus will be put on common recurring patterns of categorization and differences in categorization. It is not that obvious why languages should differ with respect to category names, since all humans do see the same world. This argument, however, could also account for the diversity of categories across languages, since it leaves open the question as to how speakers decide which structures of the input are relevant to categorization.

In fact, several studies have shown that languages vary with respect to the number and nature of the semantic categories they distinguish within a given domain. This has been substantiated for artifact categories (e.g., Malt et al. 1999) and verb categories, more specifically "cut and break" events (e.g., Majid et al. 2007; Goddard/Wierzbicka 2009) and "put and take" events (Kopecka/Narasimham 2012) as well as for verbs denoting emotion, more specifically pain (Reznikova et al. 2012). Another example of how languages differ in their categorization can be cited with respect to taxonomic depth, where the lexical inventory of satellite-framed languages (S-languages) seems to offer many hyponyms for manner-of-motion verbs. In German, e.g., schlendern, bummeln, and trotten can all be considered hyponyms of gehen 'walk', whereas verb-framed languages (V-languages) do not show variation along these lines (for detailed examples, see, e.g., Slobin 2006).

The present study examines in detail how speakers of two S-languages, German and Danish, and one V-language, Turkish, describe motion events, with special focus on the extension of terms in semantic space (i.e., their "range of meaning") and taxonomic depth (i.e., how many hyponyms there are). Differences in the extension of verbs across languages, as made visible by cluster analysis, are accounted for by particularly considering typological factors. Commonalities are accounted for in terms of natural constraints, which may give rise to common cross-linguistic ways of conceptualizing motion.

\section{Review of literature}

\section{$2.1 \quad$ Lexicalization}

In Talmy's motion event typology, the basic assumption is that motion can be considered a universal cognitive concept that is lexicalized across languages. Differences across languages arise with respect to how the framing event, i.e., the motion as such, is expressed (Talmy 2000b: 226-228, 1991: 488-490).

The Figure is a moving or conceptually movable entity whose site, path, or orientation is conceived as a variable the particular value of which is the relevant issue. The Ground is a reference entity, one that has a stationary setting relative to a reference frame, with respect to which the Figure's site, path, or orientation is characterized (Talmy 2000a: 184). 
Hence, elements that constitute a motion event are:

a. Figure: the moving entity;

b. Ground: the object in relation to which the Figure is moving;

c. Path: trajectory of the Figure's movement, i.e., the association function between Figure and Ground;

d. Motion: the actual movement or activating process; and

e. the Co-event: manner or cause of the motion.

Depending on where the Path element is expressed in the sentence, Talmy suggested a twoway typology for the languages of the world: Verb-framed languages (V-languages), for languages that encode the Path element in the verb, and Satellite-framed languages (Slanguages), encoding the Path element outside the verb.

Descriptions of the participants shall serve as examples, see (1) to (3):

(1) German (S-language)

Die Affen gehen um den Baum herum.

The monkeys walk around the tree around.

'The monkeys walk around the tree.'

(2) Danish (S-language)

To aber går rundt om et trae.

Two monkeys walk around around a tree.

'Two monkeys walk around a tree.'

(3) Turkish (V-language)

Maymunlar ăgacin etrafinda dönüyor.

Monkeys tree's side circle.

'Monkeys circle a tree.'

This kind of typological classification often crosscuts the more traditional word order typologies. With respect to these typologies, Danish, English, and Spanish fall into the same group, SVO (subject - verb - object), whereas Turkish belongs to the SOV (subject - object verb) group. German is often referred to as lacking dominant word order, employing SVO in main clauses and SOV in sub-clauses. However, in Talmy's motion verb typology, Spanish and Turkish belong to the same group, and German falls together with English and Danish. In the remainder of the paper, 'typology' and 'typological' are used to refer to the Talmian binary typology, unless stated otherwise.

Studies applying Talmy's binary typology to find out how conceptual structures might influence linguistic structure have mostly shown that the lexicons of S-languages contain a wider variety of manner-of-motion verbs (e.g., dash, swoop, scramble). The speakers of these languages tend to provide more frequent and varied manner information than speakers of $\mathrm{V}$ languages when describing motion events (see Slobin 2004 for an overview; Özçalişkan/Slobin 1999 for Turkish in particular).

However, observations deviating from this pattern are, for example, described in a study by Naigles et al. (1998). In this study, designed stimuli rather than picture book elicitations were used. The researchers find that Spanish speakers used a higher number of motion verbs than 
English speakers. Similarly, Kopecka (2010) finds in a study looking at the expression of motion in written prose that Polish has fewer manner verbs than English.

\subsection{Categorization}

Another issue that has received growing attention in recent years is the categorization of events, for example, events involving material destruction, "cutting and breaking" events (Majid et al. 2007), or "carry" and "put" events (Bowerman 2005; Kopecka/Narasimham 2012). These studies observed cross-linguistic differences with respect to the partitioning of the semantic space. For example, English speakers can make a more fine-grained description of a cut event by choosing either cut or slice, whereas Swedish speakers do not have this option; i.e., the Swedish term skära covers 'cut' and 'slice', collapsing the distinction between the two (Majid et al. 2007).

A further domain that displays cross-linguistic differences with respect to the partition of the semantic space is the domain of motion. In a study investigating naming patterns by speakers of three different S-languages (Bulgarian, English, and Norwegian) and one V-language (Italian), Vulchanova et al. (2012) propose a more fine-grained feature analysis than the one suggested by Talmy (1991). Their parameters include, but are not limited to, locomotion media (e.g., terrestrial vs. aquatic vs. air), gait phase (e.g., suspended vs. supported vs. aerial), posture and stance (e.g., upright vs. low body; erect vs. sprawling legs), temporal spacing of footfalls (symmetrical vs. asymmetrical), and figure orientation. Discussing the importance of the features across languages, they notice that phase, posture, velocity, path, and vector orientation are relatively robust features used for distinction. They found, for example, a clear distinction between non-supported, high-velocity, high-energy gaits (running) and supported, slow-to-normal velocity motion gaits (walking) in all their languages. There were, however, differences in the categorization of "walking" events, where the speakers of the languages under investigation varied in how fine-grained they subdivided this type of motion event. This is in line with the results reported by Malt et al. (2008), who also found a categorical distinction between high- and low-velocity gaits, and a more fine-grained distinction within these two categories in English, Spanish, Japanese, and Dutch, for example the difference between shuffling and marching. Malt et al. (2008) concluded that this is because categorization is constrained by very salient, naturally occurring discontinuities that "cry out to be named" (Berlin 1982: 11). Hence, in some cases categorization seems to be more than just a matter of construction/construal on the part of the language user. These natural constraints can be of help in accounting for commonalities across languages.

As explained in detail in Malt et al. (2011) and Malt et al. (in press), one could take on two perspectives with respect to how meaning is mapped onto words, and hence where variation or common patterns respectively arise from. One perspective is that those linguistic categories carved out often and in a similar fashion across languages reflect structure in the input. In turn, variation might be due to a varying selection of features used in the lexical partitioning. To explain variation then is to identify these features and to explicate how they are applied across languages.

Furthermore, the typological structural characteristics of a language might factor into the selection of features. In Turkish, for example, Path is the element encoded in motion verbs (as 
in V-languages in general), whereas in S-languages Manner is mainly encoded in the verb. This syntactic salience seems to have given rise to a more elaborate manner verb lexicon in Slanguages and, albeit in somewhat more limited terms, to a more comprising path verb inventory for V-languages. As shown in Gennari et al. (2002), these typological differences have an influence on how scenes are encoded in memory. Thus, it might be possible that they are also relevant to other cognitive processes, in particular to categorization.

Very few studies have used cluster analysis as a tool for mapping out semantic space for a given domain so far. Two studies that made use of cluster analysis in two different verbal domains are Majid et al. (2007) and Vulchanova et al. (2012). Both studies use an extensional grid against which they map their production data. The extensional grid in both cases is composed of a set of videos. Usually, a real "etic grid" captures possible value combinations of the parameters in question (Bohnemeyer et al. 2007). However, in the studies mentioned above and in the current study, the videos are not fully controlled for certain features. Rather, they represent a very wide segment of motion-event reality in that they show a broad range of species and movements in the case of the videos collected by Vulchanova et al. (2012), or videos representing a wide scope of cutting and breaking events. Thus, the videos are especially useful for mapping out the verbal inventory of the languages in question and for collecting preferred descriptions by multiple speakers. Another advantage of the use of videostimuli over picture description or narration tasks, where motion has to be inferred, is that videos actually show the dynamic events and are thus likely more useful to trigger more naturalistic descriptions (cf. Navarro/Nicoladis 2005).

The present study contributes to the discussion of the semantics of motion events by focusing on the semantics of motion verbs. Using the same stimuli, it follows the line of investigation initiated by Vulchanova et al. (2012). The contribution is twofold: on the one hand, it will point out similarities and differences with respect to the initiating study; and on the other hand, by looking at descriptions of motion events in German, Danish, and Turkish, this contribution describes similarities and differences between the verb semantics of the languages of the experiment. In particular, it will detail taxonomic depth and extension patterns. Based on these observations, an analysis of how the typological structural properties of the languages of the experiment might contribute to word meaning is conducted. Furthermore, the analysis describes to what degree typological membership plays a role in the semantics of motion verbs.

To answer these overarching issues, this study addresses the following research questions:

1. Which verbs are used in the descriptions of the videos and how frequently?

2. What are the semantic characteristics of the motion verbs employed across the three languages in terms of

a. their extensions in the semantic space, i.e., their semantic boundaries?

b. hierarchical relations, i.e., taxonomic depth/meaning relations/structure of the semantic space across the three languages?

c. certain features as salient for categorization, i.e., parameters for segmentation? 
3. How do the semantic characteristics relate to the typological structure of the three languages? What is the relation between features and typological membership?

\section{$3 \quad$ Participants and method}

\subsection{Participants}

Native speakers of Danish $(n=21)$, German $(n=25)$, and Turkish $(n=25)$ viewed and described a series of 37 video clips. The lion's share of the participants was composed of university students or research employees; each participant was a resident in his or her native country. The participants were asked to fill out a linguistic background questionnaire based on the Language Background Questionnaire (Gullberg/Indefrey 2003). Participants generally reported a good to very good knowledge of English.

\subsection{Stimuli}

The stimuli in this study were 37 video clips, each 3 to 4 seconds long, of a great variety of motion events performed by humans, primates, and a range of different animals (Vulchanova et al. 2012). The video clips were embedded in a web page with instructions in the relevant language. Participants viewed each clip and typed into a response box. The response box was preceded by the appropriate translation of Please, describe what you see according to the native language of the participant.

Data elicitation for the three groups was mainly conducted online, with the researcher accessible in person or via chat in case of questions or technical problems. Input regarding the actual task was minimized; no hints or clues were given as to how to answer the elicitation question. This was done to prevent a possible manipulation bias. Nevertheless, even though it was web-based, this study also shares features with face-to-face studies and is not a webstudy that excludes clarification possibilities.

\subsection{Methodological assumptions}

The elicitation can be described, in the sense of Taylor (2007), as a mixture of naming; i.e., informants were asked to name a randomized series of videos in terms of mapping. They could use the same verb several times, thus indicating a possible range of motion scenes that could be named by this verb. This way, motion verbs together with their extensional range could be elicited. When all informants agreed in naming a scene by the same verb, this could be taken as indirect evidence that the scene is a good example of a verbal concept. Variable responses, on the other hand, could be considered as indirect evidence that the scene is marginal with respect to at least one of the verbs. Furthermore, it is commonly assumed that a word's extension is a function of its intension (i.e., its meaning).

Cluster analysis is considered a tool for making visible which verbs are used how frequently for which scenes. In addition, it provides information as to how the verbs used in the descriptions relate to each other; i.e., it can be used to identify several kinds of semantic relations between the verbs, such as taxonomic inclusion, synonymy, overlap (partial synonymy), and contrast. The resulting clusters can further be examined to see if there are certain common features of the clips that the verbs pick out. These features could provide a 
motivation for the lexical partitioning of the domain. However, in our case, the features to be identified as such have to be interpreted very carefully, since the clips were not controlled for predetermined features.

\subsection{Procedure}

The main verbs were extracted from the participants' answers. In the few cases in which the participants provided incomplete sentences, the verbal element of the clause was counted (e.g., en løbende abe 'a running monkey'). Other linguistic devices (e.g., adverbs or converbs) that express path or manner information are also important to the description of motion events (Talmy 1985), but an analysis of their contribution lies beyond the scope of this paper and will be the subject of another article.

A video clip-by-verb matrix (with the scenes in rows and the verbs in columns) was created for each of the three informant groups, showing the frequency of occurrence for each verb per scene. The resulting matrices were analyzed using cluster analysis. Cluster analysis is a statistical tool that allows us to group together scenes that were described with the same verb or verbs. Thus it makes visible the number of categories used for a given semantic domain, and provides information about category boundaries across languages as well as about the relationship among categories (Majid et al. 2007). For example, verbs that describe motion might have a hierarchical relationship; spadsere 'stroll', e.g., is a hyponym of gå 'walk' in Danish. The cluster analysis used in this experiment uses Euclidean distance and Ward linkage in a hierarchical agglomerative clustering. This procedure differs slightly from Majid et al.'s (2007) procedure, in that the use of a different distance measure allows for the capturing of differences in the frequency of usage of a verb (rather than just noting whether a certain verb appeared or not). Each clip starts out as a separate cluster, and then at every step the clusters are merged to form larger clusters based on similarity. In our analysis, the calculation of similarity is based on the frequency of the use of verbs across clips. To the extent that clips are described with the same verb(s), they are more similar to one another and are more likely to be in the same cluster. Clips that are never described by the same verb(s) will end up in separate clusters. Clusters are assumed to represent categories across the languages and capture the main groupings based on the distribution of verbs across the whole stimulus set.

\section{$4 \quad$ Results}

\subsection{Frequency analysis}

A simple count of the main verbs used in the speakers' descriptions revealed the following picture (Table 1): 


\begin{tabular}{|l|l|l|l|l|l|l|}
\hline & $\begin{array}{l}\text { number of } \\
\text { speakers }\end{array}$ & $\begin{array}{l}\text { number of } \\
\text { scene } \\
\text { descriptions }\end{array}$ & $\begin{array}{l}\text { number of } \\
\text { motion } \\
\text { verbs }\end{array}$ & $\begin{array}{l}\text { \% of } \\
\text { answers }+ \\
\text { motion } \\
\text { verbs }\end{array}$ & $\begin{array}{l}\text { mean } \\
\text { SimpD }\end{array}$ & $\begin{array}{l}\text { number of } \\
\text { type of } \\
\text { motion } \\
\text { verbs }\end{array}$ \\
\hline Turkish & 25 & 925 & 825 & 89.19 & 0.5 & 36 \\
\hline German & 25 & 925 & 919 & 99.35 & 0.4 & 69 \\
\hline Danish & 21 & 777 & 646 & 79.36 & 0.6 & 41 \\
\hline
\end{tabular}

Table 1: Summary of frequency analysis

German speakers used the highest number of different motion verbs $(n=69)$, followed by Danish speakers $(n=41)$ and Turkish speakers $(n=36)$. Almost every description by the German speakers included a motion verb (99.35\%), compared to $89.19 \%$ of the Turkish speakers' descriptions and $79.36 \%$ of the Danish speakers' descriptions. In the cases where no motion verbs were used, participants generally reported on the context ("training" for scenes in the gym, "participating in a race" for the scene depicting a walking competition, or more general descriptions like "a dog in a cage").

\subsubsection{Agreement between speakers}

In order to determine the degree of agreement in the naming patterns as expressed by the speakers of the three languages, Simpson's Diversity Index (D) ${ }^{1}$ was calculated (following Majid et al. 2007). D captures both the number and the distribution of verbs used. The higher the value of $\mathrm{D}$, the more consistency there is in the responses; in other words, there is a higher likelihood that speakers of a given language use the same verb to describe a given scene. D was measured for each clip and for each language separately. Then the mean D for each

\footnotetext{
${ }^{1}$ Simpson's Diversity Index can be explained in the following manner: We are interested in how diverse the speakers' use of verbs for a given scene is. In order to measure this diversity, we first count all the different verbs used for describing a given scene. Let $\mathrm{V}=\{\mathrm{v} 1, \mathrm{v} 2, \ldots, \mathrm{vM}\}$ be the set of unique verbs used by the speakers to describe the scene in question. Suppose there are a total of $M$ such verbs. Furthermore, suppose verb vi is observed ni times. Let $\mathrm{N}$ denote the total number of responses collected for a scen; consequently, $N=\sum_{i=1}^{M} n_{\mathrm{i}}$. One can then easily compute the share of each verb within all the responses as the ratio of the number of times a given verb is used and the total number of responses. That is,
}

share of $v_{1} \equiv s_{i}=\frac{\text { number of times } v_{1} \text { is used }}{N}=\frac{n_{i}}{N}$

When speakers use a large variety of verbs, naturally the share of each verb will be very small, provided we have a sufficiently high number of total responses and a rather diverse set of responses. On the other hand, when the speakers use only a few verbs to describe the scene, each verb will have relatively high shares and we would have a quite concentrated set of responses. Simpson's Diversity Index is a commonly used measure of diversity (or, alternatively, concentration) that summarizes the above intuition for a given set of responses and is calculated on the basis of the following formula:

$D=\sum_{\mathrm{i}=1}^{M} \frac{n_{\mathrm{i}}\left(n_{\mathrm{i}}-1\right)}{N(N-1)}$

If one verb is used in most of the responses, that verb will have a very high share while all the others will have small shares, implying a large value of D. If one verb is used by all the respondents, D will take a value of 1 . On the other hand, if all $\mathrm{N}$ responses contain a unique verb in the description, the contribution of each verb in the above sum will be exactly 0 , and $\mathrm{D}$ will take the value of 0 , indicating a very diverse set of responses. 
language was calculated to assess the overall consistency for each language. Danish speakers were the most consistent (D 0.7), followed by Turkish speakers (D 0.5) and German speakers (D 0.4). This result is in line with respect to the number of different types used by speakers of each language, where German speakers used the highest number of different verb types.

\subsubsection{The gloss trap}

A remark on the role of the glosses used in this paper seems important. The "gloss trap", as described by Stringer (2010: 102: "it is extremely difficult to find true matches in the openclass lexicons of any two languages), is a notion that is highly relevant to this study. Since one of the main points is to show that motion verbs across languages describe very different areas of the semantic space of motion, it almost seems beside the point to provide English glosses, as these most certainly will not cover the exact same meaning as the term they are used to gloss. However, to give the reader a feel for the wide variety of meanings encoded, glosses will be provided. The reader is kindly asked to handle these glosses not as translation equivalents, but merely as weak pointers to a possible common meaning.

\subsubsection{Verbs used}

For each language, the overall number of verbs was counted together with the frequency of a verb used to describe a given clip. The Danish speakers produced the simplest pattern: $75 \%$ of all the scene descriptions included either kravle 'crawl' (25.7\%), løbe 'run' (25\%), or gå 'walk' (23\%). For Turkish and German speakers, the patterns were less simple, since the three most frequently used verbs account for $47.6 \%$ and $61.2 \%$ of all scene descriptions. The verbs in Turkish were yürümek 'walk' (26.5\%), koşmak 'run' (17.8\%), and ilerlemek 'move forward' (16.9\%). The verbs used by German speakers were laufen 'run/walk' (23\%), krabbeln 'crawl' (12.6\%), and gehen 'walk' (12.1\%). A complete list of the motion verbs used together with their frequencies can be found in the Appendix.

The simple frequency count and the level of agreement among speakers seem to point to a language-dependent segmentation of the semantic space. The very high number of motion verb types used by German informants was reflected in the relatively low degree of agreement in the scene descriptions.

\subsection{Cluster analysis}

To gain a deeper understanding of the structure of categories underlying the informants' descriptions (or simply put: to get an overview as to which verbs can be used for which scenes), a cluster analysis of the collected data was conducted. The following sections describe the results of respective cluster analysis for the individual languages, first for Danish, followed by German, and finally for Turkish.

\subsubsection{Danish}

Figure 1 shows the result of the cluster analysis for Danish. 


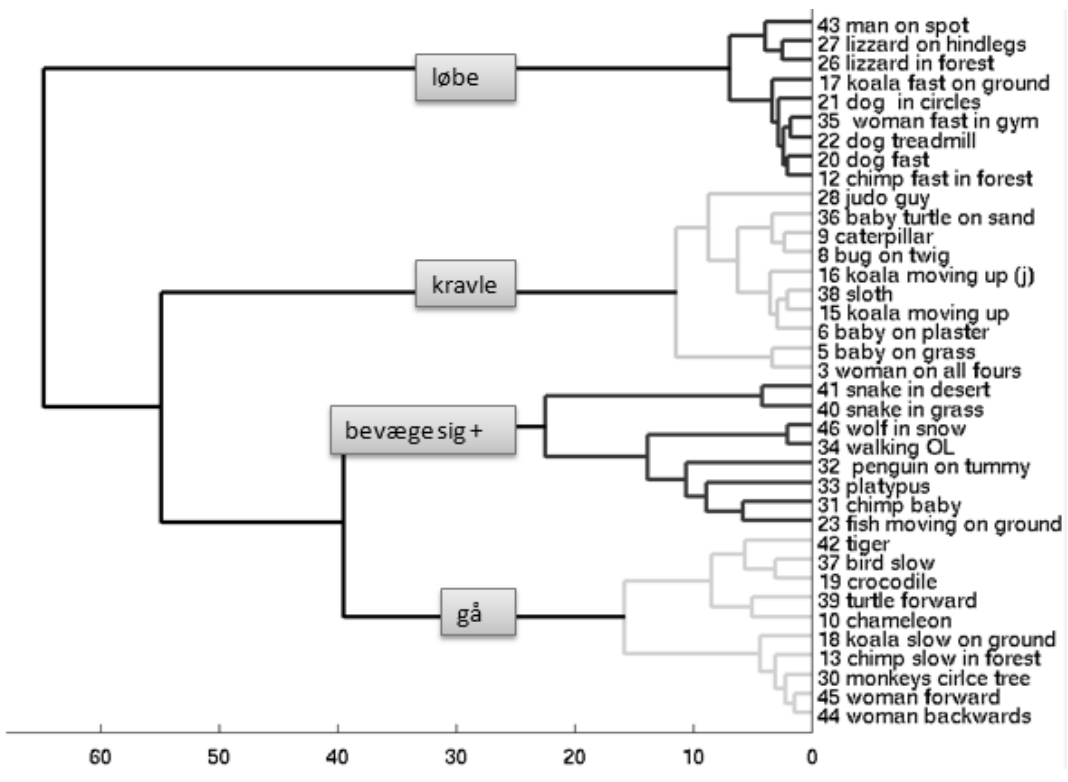

Figure 1: Cluster tree for Danish

For Danish, the cluster analysis confirmed the semantic categories obtained in the frequency analysis. Native speakers of Danish partitioned the semantic space presented in the video clips into four main categories. As illustrated in Figure 1, three categories reflect the use of the three most frequent verbs: løbe 'run', gå 'walk', and kravle 'crawl', describing fast vs. slow movement forward, and slow movement with close contact to a ground/surface. The fourth category is defined by a frequent use of the general motion verb bevage sig 'move', as well as a variation of rather specific motion verbs (e.g., mave sig 'move on tummy', sno sig 'slither').

The bevage sig cluster seems to function as a residual class, as it comprises events that do not fit into the other categories. These events include a fish moving forward on the ground using its fins and a baby sea turtle trying to reach the water through deep sand. It also contains two scenes showing two different snakes moving.

A categorical distinction is present in Danish between high-velocity gait and slow gaits, which are further subdivided into kravle 'crawl' and $g a ̊$ 'walk' events (also observed by Malt et al. 2008 and Vulchanova et al. 2012). The likely parameter for the distinction between kravle and $g a ̊$ seems to be visible use of legs/limbs $(g a ̊)$ and/or close contact to the surface (kravle).

With respect to taxonomic depth, the majority of the less frequently used motion verbs could be considered to be more specific versions of the main clusters. The verbs that were used in variation on løbe and gå are more fine-grained with respect to their semantics (e.g., fise 'sprint', spcene 'sprint' as hyponyms for løbe; and spankulere 'stroll', slentre 'saunter' as hyponyms for gå.) Interestingly, no hyponym for kravle appeared in the data. However, the verbs that predominantly occur in variation on bevage sig can be regarded as hyponyms of krybe 'creep', e.g., mave sig 'move on tummy' or orme sig 'move like a worm'. Krybe is not used very often. Most hyponyms in the data represent kinds of running, followed by hyponyms for walking. 


\subsubsection{German}

For German, the frequency analysis and Simpson's Diversity Index pointed to a less unanimous picture with respect to the semantic categories, as illustrated in Figure 2. The cluster analysis reveals that the categories for German are not as clear-cut as those for Danish. There are two types of categories: categories that are clearly defined by the use of one single verb across speakers, and categories that show the recurrent use of several verbs across speakers.

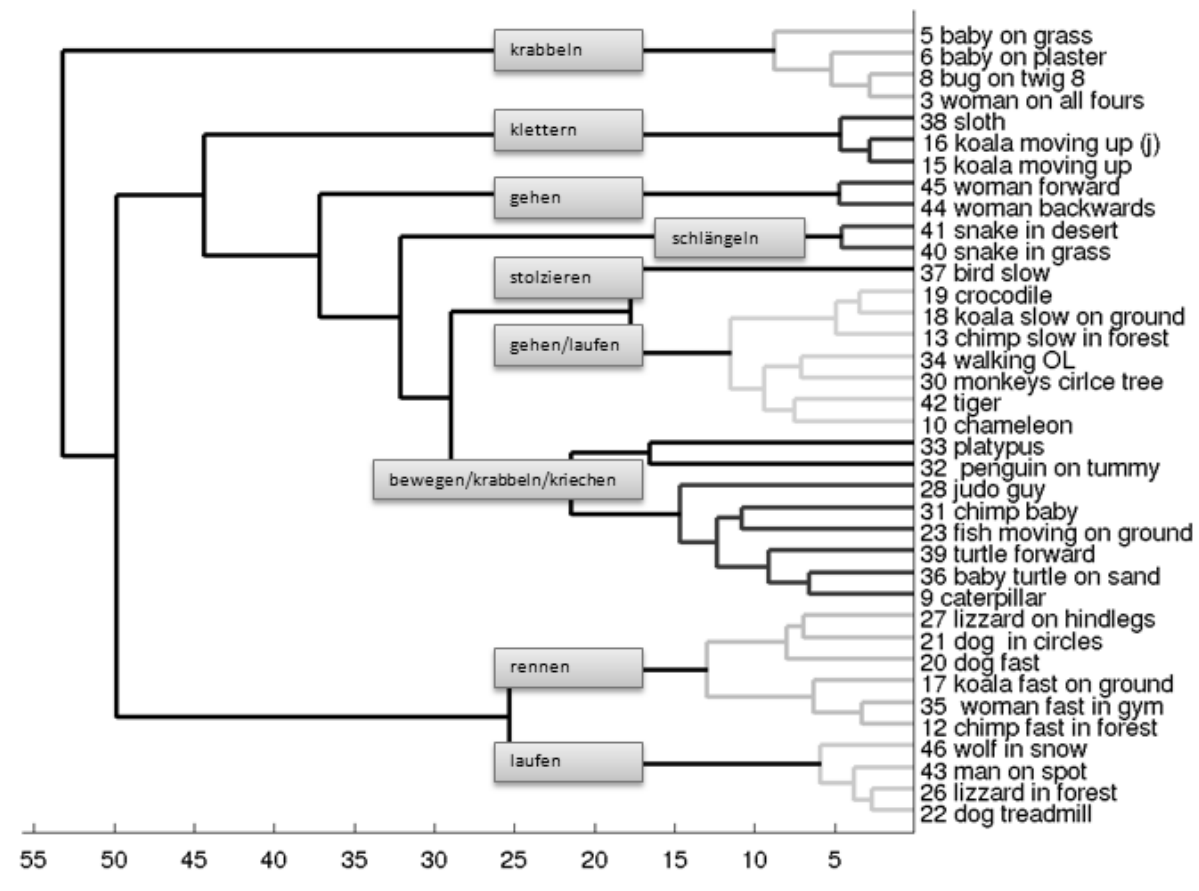

Figure 2: Cluster tree for German

The categories that are clearly defined by the use of one verb are krabbeln 'crawl', klettern 'climb', gehen 'walk', schlängeln 'slither', and laufen 'run' (fast). The categories that show a regular variation of same type verbs are laufen/gehen 'run/walk', bewegen/krabbeln/kriechen 'move/crawl/creep' - with a slightly more frequent use of bewegen 'move' compared to the other verbs, and laufen/rennen 'run/spurt'. The most frequent German verb laufen occurred in three of the categories, which indicates a broad meaning.

Many of the verbs that were less frequently used can also be identified as more fine-grained alternatives to gehen 'walk', e.g., schlendern 'amble', schreiten 'stride', or as alternatives to laufen 'run', e.g., flitzen, sausen 'dash'. Hyponyms of gehen/laufen (slow) show the highest variability, followed by laufen (fast). Verbs within the bewegen/krabbeln/kriechen cluster cannot be described in terms of hyponymy, but rather represent very specific classes themselves, e.g., paddeln 'moving as if using a paddle', or schaufeln 'moving as if using a shovel'.

Two of the distinct categories seemed to be motivated by the moving figure: sich schlängeln 'slither' for the scenes that show two different kinds of snakes moving, and stolzieren 'strut, move on long legs' for the scene depicting a long-legged bird walking. Stolzieren is used in competition with laufen (slow) and seems to collocate with nouns referring to birds with long legs. 


\subsubsection{Turkish}

For Turkish, the frequency analysis and Simpson's Diversity Index suggested that it lay between German and Danish with respect to well-defined categories, as illustrated in Figure 3.

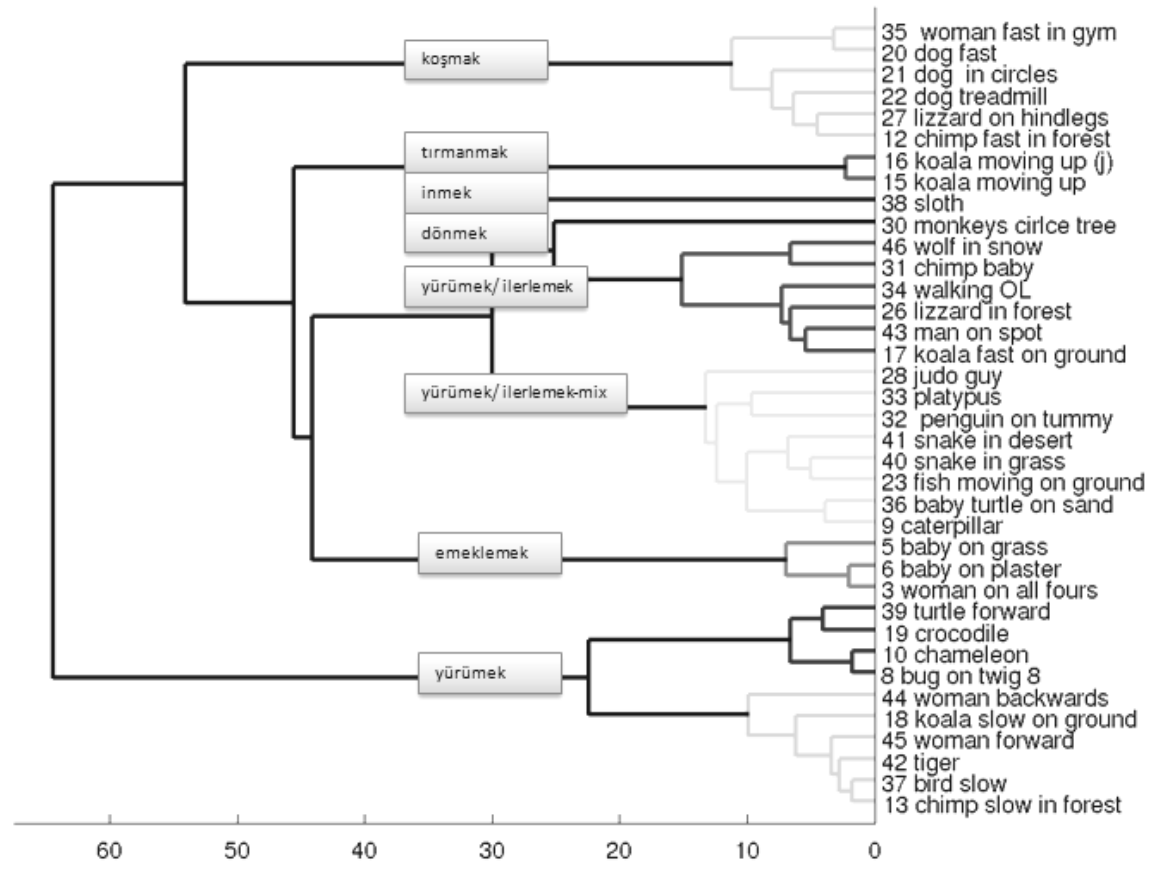

Figure 3: Cluster tree for Turkish

Clearly defined categories are inmek 'move down', dönmek 'turn', ilerlemek 'move forward', tırmanmak 'climb up', emeklemek 'crawl', yürümek 'walk', and koşmak 'run'. One category that shows an even distribution of two verbs is yürümek/ilerlemek 'walk/move forward'. The cluster analysis further produced a cluster that is characterized by a large degree of variation in the choice of motion verbs, the yürümek/ilerlemek mix-cluster.

For four of the categories (inmek 'move down', dönmek 'turn', ilerlemek 'move forward', and tırmanmak 'climb up'), vector orientation is the motivating feature. For yürümek 'walk' and koşmak 'run', the salient feature seems to be speed (normal vs. fast). Thus, like Danish, Turkish also displays a categorical distinction between high-velocity events and slow events. Fast events are described by koşmak 'run' and include scenes showing, among others, a chimp running into a forest and a dog running very fast around a tree.

With respect to taxonomic depth, Turkish displays a greater variety of parallel definite categories, but it is hard to determine whether there is taxonomic depth at all. The data show some variation for emeklemek 'crawl', with one of the potential hyponyms being apalamak, which can only be used to describe a baby's movement. In the Turkish data, there were two verbs that encode 'moving forward': hareket etmek and ilerlemek. Furthermore, there are four different verbs that can very loosely be translated as 'to wander': dolaşmak, dolanmak, gezmek, and gezinmek. These terms seem to vary along the lines of purposefulness or state of mind. Another example of motivating parameters being related to a certain state of mind might be koşturmak 'run slowly/jog because of being in a hurry'. So, if there is taxonomic 
depth in Turkish, it seems to be motivated by "a state of mind"-frame rather than a "kind of"frame.

\section{Comparison across languages}

As shown in the previous section, the languages under investigation differed in the number of categories used to describe the semantic space of motion, which goes hand in hand with different extension patterns and regarding taxonomic depth. First, let us consider the latter.

With respect to taxonomic depth, the languages under investigation distinguished different numbers of hyponyms for different hypernyms. German speakers offered the highest degree of variation with respect to more fine-grained distinctions; Danish speakers used more hyponyms than Turkish speakers, whereas Turkish speakers used more categories than Danish speakers. This is also reflected in the degree of consistency of responses.

To illustrate, Turkish appears to have the least variation with respect to hyponyms. As discussed above, one hyponym for emeklemek 'crawl', apalamak, occurred in the data. It was only used once. Furthermore, four terms that denote 'moving around aimlessly' - dolaşmak, dolanmak, gezmek, and gezinmek - seem to be hyponyms of yürümek 'walk' in the data. Nevertheless, in general, the moving can also be done by foot, vehicle, etc. Hence, these four verbs do not just represent different kinds of walking. Moreover, there was virtually no taxonomic depth within the path verb categories; i.e., scenes described by inmek 'move down', tırmanmak 'climb up', and dönmek 'turn' were almost exclusively described by those verbs. One exception can be seen in dönmek 'move around' and daire cizmek 'draw a circle', where the latter, however, is used in a figurative fashion, and in the use of clkmak 'exit' instead of inmek 'move down', which occurred only once.

Vertical variation within categories in German and Danish was observed within the manner verbs, with German speakers using the highest number of terms in more fine-grained descriptions of gehen/laufen 'run/walk', (taumeln 'sway', schreiten 'stride', stelzen 'stalk', trotten 'trot', and tapern 'totter', to name just a few) and Danish speakers of løbe 'run' (e.g., fise 'dash', spcene 'sprint', and pile 'dash').

The languages also varied with respect to how they semantically categorize motion events; i.e., they varied with respect to the building block meanings assigned to the verbs. Before considering three examples, a note of caution seems appropriate: As mentioned above, the principles of categorization that might create the given segmentation of the languages in this study can only be assessed tentatively, since the stimuli clips were not controlled for varying features or components. However, a comparison of the segmentation lines across the languages does reveal some interesting patterns, as illustrated by Figures 4 to 6 .

First, Danish grouped slow-velocity and close contact to the surface events together, making no distinction in the verb as to upward or downward motion (i.e., kravle 'crawl' events). Figure 4 shows the extension pattern of the Danish verb kravle 'crawl', i.e. those scenes for which kravle was the dominant verb used. These scenes include two scenes showing a koala moving up a tree, once in a "normal" fashion and once in a jumping manner; a sloth moving down a tree; a baby turtle moving forward in sand; a baby crawling on grass; a baby moving 
forward on stretched limbs; a bug and a caterpillar moving on a twig; a woman moving forward on all fours; and a man moving forward on the ground using his knees and elbows.

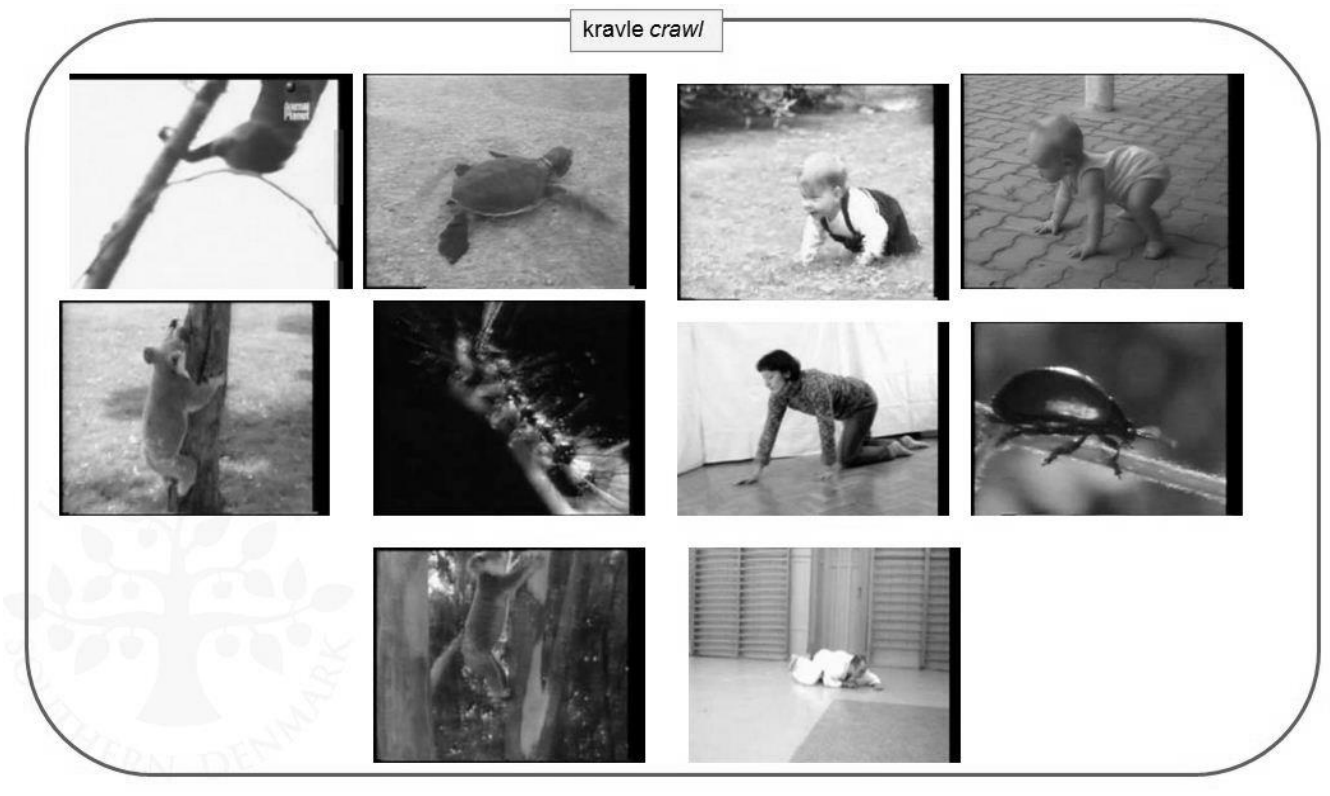

Figure 4: Extension pattern of Danish kravle 'crawl'

In contrast, Figure 5 shows how Turkish speakers segmented the same section of the semantic space. Movement along a vertical axis, as represented by the koala clips and the sloth clip, was separated into movement upward (tirmanmak 'climb up') and movement downward (inmek 'move down'). Thus, the distinction of categories into "upward" or "downward" movement seems obligatory. Furthermore, the bug moving forward on a twig belongs to the yürümek category, together with, for example, a woman walking. This points to a semantic conceptualization of a bug's movement, which is closer to a person walking than to a person crawling. The use of emeklemek 'crawl' was restricted to the three scenes showing babies moving on all fours and the woman moving on all fours. One speaker used it to describe the movement of the judoka. This might point to the fact that the use of emeklemek cannot easily be extended to non-human entities. The remaining three scenes showed movements that seem not to have been judged conceptually similar enough to fit a clearly defined category; hence, they were described by the very general motion verb ilerliyor 'move forward'.

As discussed above, Turkish speakers seem to be sensitive to vector orientation as a parameter for segmentation. Four of the categories that describe the motion domain were named by the use of a path verb, namely inmek 'move up', dönmek 'turn', ilerlemek 'move forward', or by tırmanmak 'climb up', which comprises manner as well as path information (cf. Özçalişkan/Slobin 1999). Typological membership might thus be considered a potential factor accounting for divergences in the motion domain. 


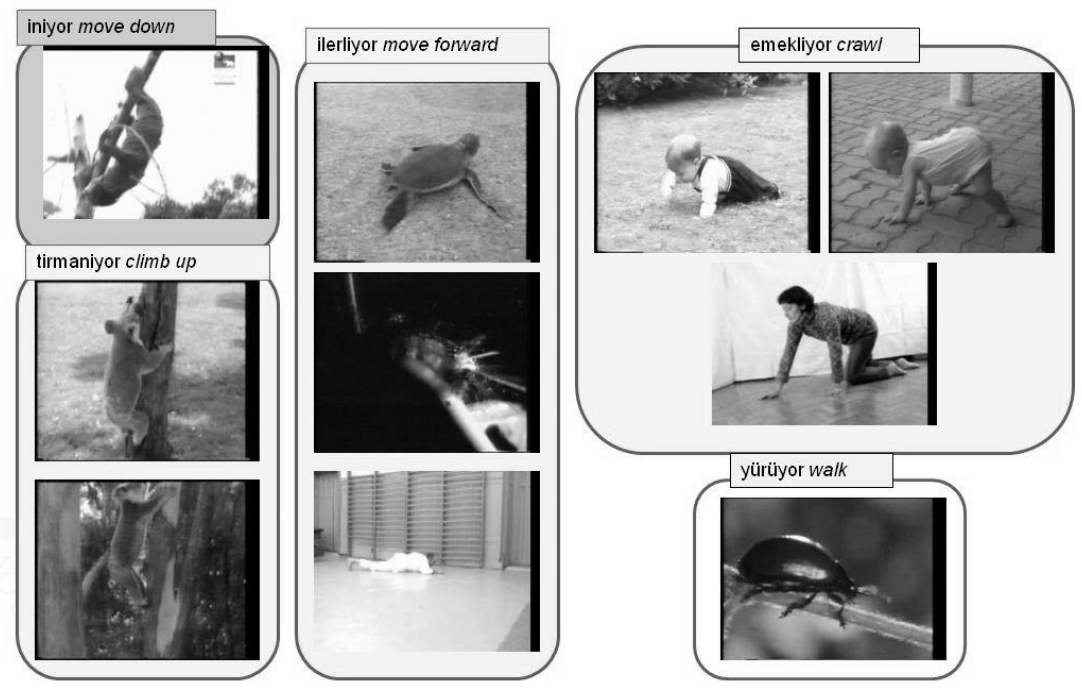

Figure 5: Segmentation of kravle scenes by Turkish speakers

Figure 6 shows the segmentation by the German informants. The divergence from the Danish motion verb kravle 'crawl' occurred according to seemingly different processes of semantic categorization. German speakers distinguished motion on a vertical axis from horizontal movement, as marked by the use of klettern 'climb' (for a movement up or down with close contact to the surface) and krabbeln 'crawl' (horizontal movement with close contact to the ground). However, unlike Turkish, German seemed to lack a distinction solely motivated by vertical vector (inmek 'move down' vs. tirmanmak 'climb up'). Thus, it can be hypothesized that the obligatory distinction is between horizontal and vertical movement. Another distinction, as compared to the Danish kravle category, was drawn between movement with close contact to the ground using legs/limbs, thereby permitting some space between the ground and the figure ( $k$ rabbeln 'crawl'), and the lack of space between ground and figure (kriechen 'creep'). Additionally, the movement of the bug on a twig appears to be conceptually more similar to the babies and the woman moving on all fours, since the speakers describe it by the same verb, krabbeln. Lastly, the German speakers used a very specialized term for the movement of the man on the floor of the gym, robben 'move like a seal'. 


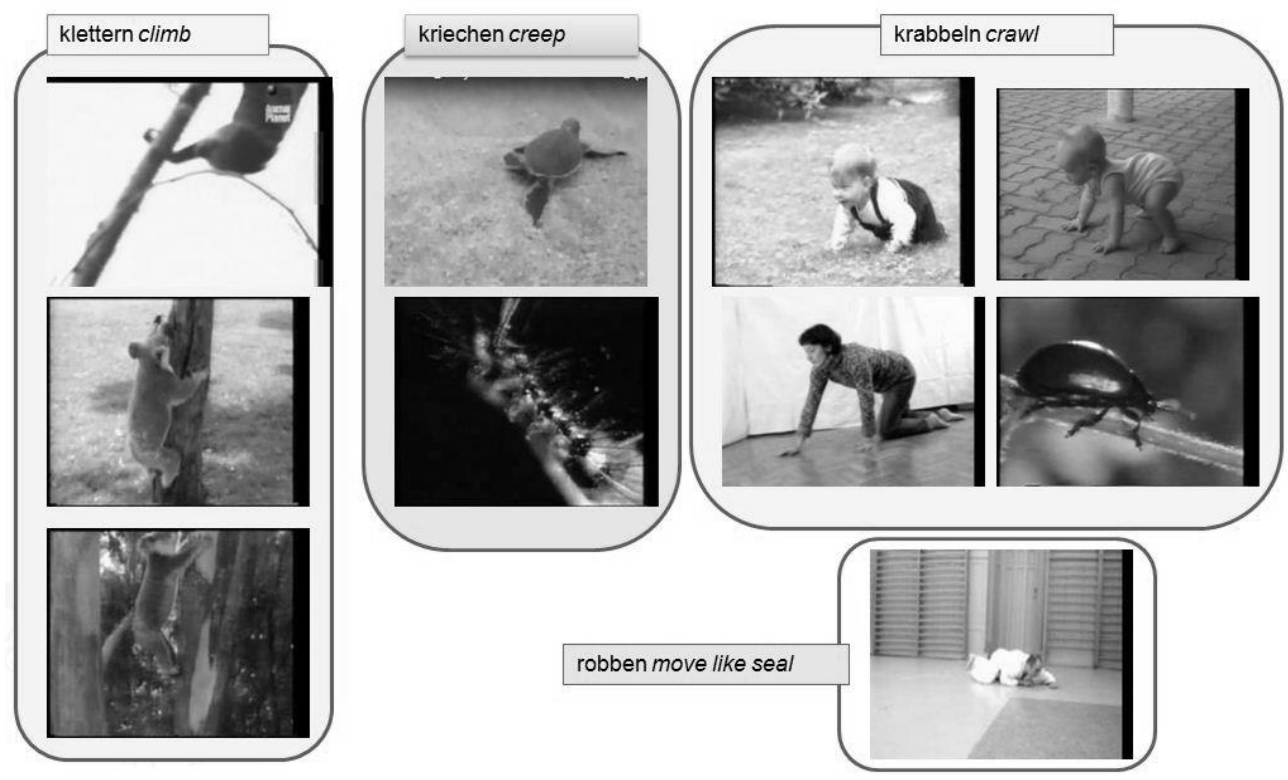

Figure 6: Segmentation of kravle scenes by German speakers

The second example to show how the meanings assigned to the verbs differ across languages involves the gehen/laufen cluster in German. Whereas there is a clear distinction between high and low-velocity gaits in Danish - as marked by the use of løbe 'run' for fast events - and Turkish, koşmak 'run', this distinction seems to be made abundant by the German speakers' use of laufen 'run/walk' for both slow and fast kinds of events. It can clearly be used to cover the semantic feature 'higher than normal speed', as in the pure laufen cluster. However, it cooccurs with gehen 'walk' in all slow, upright-gait events. For example, laufen and rennen 'run' are used in the description of a lizard moving very fast on his hind legs, whereas laufen and gehen 'walk' are used in the description of a scene depicting an alligator moving to the sea at a slow pace, its legs clearly visible. Thus, the common denominator appears to be the use of limbs rather than velocity.

\section{Discussion and conclusion}

Overall, the present study shows that the extension patterns of semantic categories used to describe motion events across the three languages of the experiment vary considerably. Turkish displays a categorization pattern that is different from German and Danish in that it shows verbal categories that seem to be constructed around path information, thus hinting at the role of structural properties in categorization. These structural properties give rise to intertypological differences. In addition, the differences between German and Danish appear to be relatively grave as well, concretely speaking with respect to "fine-grainedness" or taxonomic depth. These intra-typological differences can be accounted for in terms of how different features are selected for categorization.

The frequency analysis offered a first indication of where the differences might be located. The languages varied with respect to verb type frequency and the most frequently used verbs (Danish kravle 'crawl', German laufen 'run/walk', and Turkish yürümek 'walk'). The cluster analysis in turn revealed more specific differences in both the category boundaries of the verbs used and the hierarchical patterning. In other words, it made visible the extension patterns of the verbs used. 
More specifically with respect to categorization, the clustering of the Turkish data suggested that patterns of variability in the category boundaries are both motivated by manner components as well as path components. Categories that are constructed around a path component/vector orientation are tırmanmak 'climb up', inmek 'move down', and dönmek 'turn'. In other words, all the motion events that display a vector different from a horizontal orientation are expressed by using a path verb. Scenes displaying a horizontal vector orientation are described by a manner verb or a path verb (ilerlemek, hareket etmek), especially if the manner displayed seems marginal in relation to other exemplars of a possible category. This seems to point to the fact that the inherent typological structure of Turkish can at least partially be taken into consideration when accounting for the semantic boundaries in the motion domain. Additionally, Turkish showed the least taxonomic depth. The highest variation of more fine-grained distinctions was found in the use of dolanmak, dolaşmak, gezmek, and gezinmek 'wander', which occurred along with the use of yürümek 'walk'. As observed before (e.g., Slobin 2006), V-languages display a less elaborated lexicon for motion verbs. This is reflected in our data by a lack of hyponyms. As a matter of fact, it seems hard to imagine an infinite number of "kinds of path" as opposed to "kinds of manner". Here again it seems that there exists a relation between typology and the mapping of conceptual content to words.

The German and Danish data suggested that mainly manner of motion components provide a base for categorical boundaries. However, the cluster analysis of the German data showed that German speakers draw more distinctions than Danish speakers, e.g., by means of two categories that seemed to be motivated by the moving figure: sich schlängeln 'slither' for the scenes that show two different kinds of snakes moving, and stolzieren 'strut, move on long legs' for the scene depicting a long-legged bird walking. This means that German speakers tend to express more fine-grained distinctions, whereas in Danish only the distinction between løbe, kravle, and gå is dominant. In addition, looking at the overall number of motion verbs used, Danish speakers used 41 different verbs, whereas German used 69, which puts Danish closer together with Turkish speakers who used 36 different motion verbs. One would have expected a difference between German and Danish on the one hand, representing expectedly lexically rich S-languages, and Turkish on the other hand. However, in this respect, Danish is closer to Turkish. It can only be speculated why this is the case. Here the influence of typological membership seems to be minor. The assumed correlation between inventories and typological membership might not be straightforward, especially when taking into account the observations made by Naigles et al. (1998) and Kopecka (2010).

The cluster analysis was also used to locate the boundaries of the extensions of similar or corresponding verbs in different languages. The extensional approach showed that conceptual equivalence is cross-linguistically rather limited. For example, while for Danish and Turkish a clear distinction between fast and slow movement was found, this distinction was blurred in German, in that laufen 'run/walk' was used by speakers to describe both high and low-velocity events. A similar observation for German was reported in a study that replicated the Malt et al. (2008) study (Phelps/Duman 2012). This is especially interesting because the distinction between slow and fast events has been argued to be motivated by perceptually very salient distinctions in nature, and hence has been assumed to apply cross-linguistically. Vulchanova et al. (2012) showed this distinction for Bulgarian, English, Italian, Norwegian, and Russian, 
and Malt et al. (2008) for English, Japanese, Spanish, and Dutch. However, this study showed that this salient distinction in nature should be seen as rendering a strong tendency, rather than a universally linguistically applicable distinction.

Another observation in this study is in line with findings in Vulchanova et al. (2012); the conceptual scope of corresponding words for crawl is rather language-specific. For Danish, the category kravle seems to be centered around a notion of "figure in close contact with substrate" with no distinction between vertical and horizontal movement, thus displaying a rather large extension. In the case of German, the limitation of this category is to be found with respect to vector orientation, where a distinction is made between vertical vs. horizontal orientation. The corresponding category in Turkish, emeklemek, is limited to "humans in close contact to ground" and vertical vector orientation. Thus, the distinctions across languages can be captured in terms of features; however, how the features are applied seems to be languagespecific.

With respect to the conceptual scope of less frequently used verbs, two things can be noted. First, the more fine-grained manner distinctions are not only more specific in terms of physical differences, as claimed by Vulchanova et al. (2012), but they also reflect intentions or mental states, e.g., the difference between German gehen 'walk' and schlendern 'walk for fun'. Slobin (2006) refers to this as attitude:

"Manner" is a cover term for a number of dimensions, including motor pattern (e.g., hop, jump, skip), often combined with rate of motion (e.g., walk, run, sprint) or force dynamics (e.g., step, tread, tramp) or attitude (e.g., amble, saunter, stroll), and sometimes encoding instrument (e.g., sled, ski, skateboard), and so forth (Slobin 2006: 3).

Second, the patterns of more fine-grained distinctions seem to be highly language-specific and instances of convention with respect to (in the sense of Malt et al. 1999) the choice of features for categorization. In other words, speakers might not be aware of any particular motivation of features they use as a basis for grouping, and features may vary across languages. To illustrate, the bug moving along a twig is categorized as krabbeln 'crawl' by German speakers, but as yürümek 'walk' by Turkish speakers. The physical features of the bug are attended to differently in the two languages. It cannot be said for sure why German speakers see a higher similarity of a bug's movement to a baby's movement; it could be the round shape or the fact that the figure is moving close to the ground. The fact that the figure's legs are visible seems to sanction the use of yürümek over emeklemek in Turkish, along with the fact that emeklemek seems to be restricted to human motion. To further illustrate the role of convention or the language-dependent choice of features in a meaning assigning process, let us look at Danish low-frequency manner verbs. Some of the verbs follow a pattern that can tentatively be described as "moving like object x", e.g., orme sig 'move like a worm' or pile 'move like an arrow'. The same pattern was not found in the German data. However, the German data showed a pattern that could be described as "moving as if using x", e.g., sich schaufeln 'move as if using a shovel' and stelzen 'move as if using stilts'. Turkish data did not show similarly motivated manner of motion verbs at all. A deeper exploration of this finding is beyond the scope of the current study and is the subject of ongoing research.

In conclusion, it can be said that German and Turkish display a higher number of semantic categories than Danish, albeit at different levels. The habitual verb use by German speakers can be considered more precise since they use many different hyponyms to describe more 
fine-grained manner distinctions. In contrast, Turkish speakers display the inclusion of a vector parameter in the verbal categories. However, the use of path verbs seems to be subject to constraints, for chiefly those scenes that displayed a vector orientation different from horizontal movement (i.e., for around-, up-, and down-movement) were described by path verbs, whereas manner of motion verbs were also used by Turkish speakers for many cases of horizontal movement. Nevertheless, such a vector-based distinction is absent in the verb use of German and Danish speakers and leads to segmentation of the semantic space along different boundaries. With respect to where Path is realized, then, the languages are influenced by typological structural constraints. However, the non-use of more specific manner verbs makes Danish the most consistent language compared to German and Turkish. This degree of consistency is not in line with the expected elaborated manner lexicon of Slanguages. The number of overall observed motion verbs in Danish is much lower than in German. This adds to the observation that elaboration of the motion verb inventory as related to typological membership seems to be a tendency rather than a rule.

Overall, conventionalized feature-based categorization processes as well as, to some degree, typological membership have been shown to be a cause for the formation of the semantic categories in the motion domain across languages.

\section{References}

Berlin, Brent (1982): "Ethnobiological classification". In: Rosch, Eleanor/Lloyd, Barbara B. (eds.) (1982): Cognition and categorization. Hillsdale, NJ, Lawrence Erlbaum: 9-26.

Bohnemeyer, Jürgen et al. (2007): "Principles of event segmentation in language: The case of motion events". Language 83: 495-532.

Bowerman, Melissa (2005): "Why can't you 'open' a nut or 'break' a cooked noodle? Learning covert object categories in action word meanings". In: Gershkoff-Stowe, Lisa/Rakison, David H. (eds.) (2005): Building object categories in developmental time. Mahwah, NJ, Lawrence Erlbaum Associates: 209-243.

Gennari, Silvia et al. (2002): "Motion events in language and cognition". Cognition 83: 4979.

Goddard, Cliff/Wierzbicka, Anna (2009): "Contrastive semantics of physical activity verbs: 'Cutting' and 'chopping' in English, Polish, and Japanese". Language Sciences 31: 60-96.

Gullberg, Marianne/Indefrey, Peter (2003): Language Background Questionnaire. Nijmegen: Max Planck Institute for Psycholinguistics. http://www.mpi.nl/research/researchprojects/the-dynamics-of-multilingual-processing/tools/Lang-Hist-Quest-Engl.pdf/, accessed October 18, 2013.

Kopecka, Anetta (2010): "Motion events in Polish. Lexicalization patterns and the description of Manner". In: Hasko, Victoria/Perelmutter, Renee (eds.) (2010): New Approaches to Slavic Verbs of Motion. Amsterdam, John Benjamins: 225-246.

Kopecka, Anetta/Narasimham, Bhuvana (eds.) (2012): Events of putting and taking. A crosslinguistic perspective. Amsterdam/Philadelphia: John Benjamins.

Majid, Asifa et al. (2007): "How similar are semantic categories in closely related languages? A comparison of cutting and breaking in four Germanic languages". Cognitive Linguistics 18/2: 179-194. 
Malt, Barbara C. et al. (1999): "Knowing versus naming: Similarity of the linguistic categorization of artifacts". Journal of Memory and Language 40: 230-262.

Malt, Barbara C. et al. (2008): "Talking about walking: Biomechanics and the language of locomotion". Psychological Science 19/3: 232-240.

Malt, Barbara C. et al. (2011): "Do words reveal concepts?". In: Carlson, Laura/Hölscher, Christoph/Shipley, Thomas (eds.) (2011): Proceedings of the $33^{\text {rd }}$ Annual Conference of the Cognitive Science Society. Austin TX, Cognitive Science Society: 519-524.

Malt, Barbara C. et al. (in press): Human Locomotion in Languages: Constraints on Moving and Meaning.

Naigles Letitia R. et al. (1998): "Speaking of motion: Verb use by English and Spanish speakers." Language and Cognitive Processes 13/5: 521-549.

Navarro, Samuel/Nicoladis, Elena (2005): "Describing motion events in adult L2 Spanish narratives". In: Eddington, David (ed.) (2005): Selected Proceedings of the $6^{\text {th }}$ Conference on the Acquisition of Spanish and Portuguese as First and Second Languages. Somerville, MA, Cascadilla Proceedings Project: 102-107.

Özçalişkan, Şeyda/Slobin, Dan I. (1999): "Learning 'how to search for the frog': Expression of manner of motion in English, Spanish, and Turkish". In: Greenhill, Annabel/Littlefield, Heather/Tano, Cheryl (eds.) (1999): Proceedings of the 23 ${ }^{\text {rd }}$ Annual Boston University Conference on Language Development. Somerville, MA, Cascadilla Proceedings Project: 541-552.

Phelps, Katherine S./Duman, Steve (2012): "Manipulating manner. Semantic representations of human locomotion verbs in English and German". In: Miyake, Naomi/Peebles, David/Cooper, Richard P. (eds.) (2012): Proceedings of the $34^{\text {th }}$ Annual Conference of the Cognitive Science Society. Austin, TX, Cognitive Science Society: 857-863.

Reznikova, Tatiana/Rakhilina, Ekaterina/Bonch-Osmolovskaya, Anastasia (2012): "Towards a typology of pain predicates". Linguistics 50/3: 421-465.

Slobin, Dan, I. (2004): "The many ways to search for a frog: Linguistic typology and the expression of motion events". In: Strömqvist, Sven/Verhoeven, Ludo (eds.) (2004): Relating events in narrative. Typological and contextual perspectives. Mahwah, NJ, Lawrence Erlbaum: 219-257.

Slobin, Dan, I. (2006). "What makes manner of motion salient?" In: Hickmann, Maya/Robert, Stéphane (eds.) (2006): Space in languages: Linguistic systems and cognitive categories. Amsterdam/Philadelphia, John Benjamins: 59-81.

Stringer, David (2010): "The gloss trap". In: Han, Zhao Hong/Cadierno, Teresa (eds.) (2010): Linguistic relativity in SLA: Thinking for speaking. Clevedon, UK, Multilingual Matters: $102-124$.

Talmy, Leonard (1985): "Lexicalization patterns: Semantic structure in lexical forms". In: Shopen, Timothy (ed.) (1985): Language typology and syntactic description (Volume 3): Grammatical categories and the lexicon. Cambridge, Cambridge University Press: 36149.

Talmy, Leonard (1991): "Path to realization: A typology of event conflation". In: Hubbard, Kahleen (ed.) (1991): Proceedings of the $17^{\text {th }}$ Annual Meeting of the Berkeley Linguistics Society. Berkeley, CA, Berkeley Linguistics Society: 480-519.

Talmy, Leonard (2000a): Toward a Cognitive Semantics, Volume I: Concept Structuring Systems. Cambridge, MA/London: MIT Press. 
of Danish, German, and Turkish

Talmy, Leonard (2000b): Toward a Cognitive Semantics, Volume II: Typology and Process in Concept Structuring. Cambridge, MA/London: MIT Press.

Taylor, John R. (2007): "The semantic categories of cutting and breaking: Some final thoughts". Cognitive Linguistics 18/2: 331-337.

Vulchanova, Mila/Martínez, Liliana/Vulchanov, Valentin (2012): "Distinctions in the linguistic encoding of motion: Evidence from a free naming task". In: Vulchanova Mila/Van der Zee, Emile (eds.) (2007): Motion encoding in language. Oxford, Oxford University Press: 11-44.

\section{Appendix}

Verbs used by the informants

\begin{tabular}{|c|c|c|c|c|c|c|c|c|c|c|c|}
\hline Turkish & & & & German & & & & Danish & & & \\
\hline verb & approximate translation & freq. & $\%$ & verb & approximate translation & freq. & $\underline{\%}$ & verb & $\frac{\text { approximate }}{\text { translation }}$ & $\frac{\text { fre }}{\text { q. }}$ & $\%$ \\
\hline yürümek & walk & 219 & $26.45 \%$ & laufen & run, walk & 206 & $23.09 \%$ & Kravle & crawl & $\begin{array}{l}16 \\
6\end{array}$ & $25.70 \%$ \\
\hline koşmak & run & 147 & $17.75 \%$ & krabbeln & crawl & 112 & $12.56 \%$ & Løbe & run & $\begin{array}{l}16 \\
1 \\
\end{array}$ & $24.92 \%$ \\
\hline ilerlemek & move forward & 140 & $16.91 \%$ & gehen & walk, go & 108 & $12.11 \%$ & Gå & walk & $\begin{array}{l}15 \\
1\end{array}$ & $23.37 \%$ \\
\hline emeklemek & crawl on all fours & 58 & $7.00 \%$ & klettern & climb & 67 & $7.51 \%$ & Bevægge & move & 27 & $4.18 \%$ \\
\hline tırmanmak & climb & 50 & $6.04 \%$ & rennen & run & 66 & $7.40 \%$ & sno sig & slither, glide & 24 & $3.72 \%$ \\
\hline sürünmek & crawl & 41 & $4.95 \%$ & bewegen & move & 60 & $6.73 \%$ & komme & come & 22 & $3.41 \%$ \\
\hline dönmek & turn & 22 & $2.66 \%$ & schlängeln & move like a snake & 35 & $3.92 \%$ & glide & glide & 10 & $1.55 \%$ \\
\hline hareket etmek & move & 20 & $2.42 \%$ & kriechen & crawl, creep & 33 & $3.70 \%$ & klatre & climb & 7 & $1.08 \%$ \\
\hline gitmek & go & 19 & $2.29 \%$ & robben & move like a seal & 21 & $2.35 \%$ & mave & $\begin{array}{l}\text { move on } \\
\text { tummy }\end{array}$ & 7 & $1.08 \%$ \\
\hline inmek & move down & 19 & $2.29 \%$ & rutschen & slide & 14 & $1.57 \%$ & lunte & $\begin{array}{l}\text { sneak, creep, } \\
\text { walk silently }\end{array}$ & 6 & $0.93 \%$ \\
\hline kaymak & slide & 11 & $1.33 \%$ & schwimmen & swim & 14 & $1.57 \%$ & krybe & creep & 5 & $0.77 \%$ \\
\hline dolaşmak & go around & 7 & $0.85 \%$ & stolzieren & strut, swagger, stalk & 11 & $1.23 \%$ & møve & $\begin{array}{l}\text { glide, move } \\
\text { along }\end{array}$ & 5 & $0.77 \%$ \\
\hline kaçmak & escape, run away & 7 & $0.85 \%$ & schleichen & $\begin{array}{l}\text { sneak, creep, walk very } \\
\text { silently }\end{array}$ & 10 & $1.12 \%$ & svømme & swim & 5 & $0.77 \%$ \\
\hline gezinmek & go around aimlessly & 6 & $0.72 \%$ & schreiten & stride, pace & 9 & $1.01 \%$ & skubbe & push & 4 & $0.62 \%$ \\
\hline yüzmek & swim & 6 & $0.72 \%$ & hüpfen & hop & 8 & $0.90 \%$ & pile & $\begin{array}{l}\text { dash, move } \\
\text { like arrow }\end{array}$ & 3 & $0.46 \%$ \\
\hline koșturmak & run slowly & 5 & $0.60 \%$ & gleiten & glide, slide & 7 & $0.78 \%$ & smyge & $\begin{array}{l}\text { glide, move } \\
\text { along }\end{array}$ & 3 & $0.46 \%$ \\
\hline oynamak & play, move & 5 & $0.60 \%$ & stolpern & stumble, trip & 7 & $0.78 \%$ & snige & $\begin{array}{l}\text { glide, move } \\
\text { along }\end{array}$ & 3 & $0.46 \%$ \\
\hline daire cizmek & draw a circle & 4 & $0.48 \%$ & sprinten & sprint, spurt & 6 & $0.67 \%$ & balancere & $\begin{array}{l}\text { move forward } \\
\text { balancing }\end{array}$ & 2 & $0.31 \%$ \\
\hline cikmak & go out & 3 & $0.36 \%$ & tapsen & toddle, lumber & 5 & $0.56 \%$ & begive & move to & 2 & $0.31 \%$ \\
\hline düşmek & fall & 3 & $0.36 \%$ & watscheln & walk like a duck, waddle & 5 & $0.56 \%$ & hoppe & hop & 2 & $0.31 \%$ \\
\hline geçmek & pass & 3 & $0.36 \%$ & erklimmen & reach, conquer by climbing & 4 & $0.45 \%$ & jogge & jog & 2 & $0.31 \%$ \\
\hline gezmek & go around, visit & 3 & $0.36 \%$ & hoppeln & hop like a rabbit, lollop & 4 & $0.45 \%$ & slange & $\begin{array}{l}\text { move like } \\
\text { snake }\end{array}$ & 2 & $0.31 \%$ \\
\hline sürüklenmek & be dragged & 3 & $0.36 \%$ & trotten & trot & 4 & $0.45 \%$ & slentre & stroll & 2 & $0.31 \%$ \\
\hline takip etmek & follow & 3 & $0.36 \%$ & besteigen & ascend, mount, climb & 3 & $0.34 \%$ & snegle & $\begin{array}{l}\text { move like } \\
\text { snail }\end{array}$ & 2 & $0.31 \%$ \\
\hline yarıșmak & race & 3 & $0.36 \%$ & fliehen & flee & 3 & $0.34 \%$ & spadsere & stroll on foot & 2 & $0.31 \%$ \\
\hline adim atmak & step & 2 & $0.24 \%$ & joggen & jog, run & 3 & $0.34 \%$ & spæne & dash & 2 & $0.31 \%$ \\
\hline koșturulmak & be made to run & 2 & $0.24 \%$ & $\begin{array}{l}\text { Schritte } \\
\text { machen }\end{array}$ & take steps & 3 & $0.34 \%$ & spankulere & stroll on foot & 2 & $0.31 \%$ \\
\hline süzülmek & glide & 2 & $0.24 \%$ & umrunden & go, walk, drive around sth. & 3 & $0.34 \%$ & spurte & spurt & 2 & $0.31 \%$ \\
\hline akmak & flow & 1 & $0.12 \%$ & verfolgen & follow, chase & 3 & $0.34 \%$ & tumle & toddle & 2 & $0.31 \%$ \\
\hline apalamak & crawl for a baby & 1 & $0.12 \%$ & walken & like "Nordic Walking" & 3 & $0.34 \%$ & vandre & hike, walk & 2 & $0.31 \%$ \\
\hline dolanmak & go around aimlessly & 1 & $0.12 \%$ & wandern & wander, roam & 3 & $0.34 \%$ & bugte & move in bows & 1 & $0.15 \%$ \\
\hline gelmek & come & 1 & $0.12 \%$ & balancieren & move balancing & 2 & $0.22 \%$ & falde & fall & 1 & $0.15 \%$ \\
\hline gerilemek & move backwards & 1 & $0.12 \%$ & flitzen & $\begin{array}{l}\text { move as fast as an arrow, } \\
\text { dart }\end{array}$ & 2 & $0.22 \%$ & fare & travel & 1 & $0.15 \%$ \\
\hline kaybolmak & become lost & 1 & $0.12 \%$ & flüchten & flee, escape & 2 & $0.22 \%$ & fise & dash & 1 & $0.15 \%$ \\
\hline kovalmak & chase after & 1 & $0.12 \%$ & hopsen & hop, jump for joy & 2 & $0.22 \%$ & flygte & escape & 1 & $0.15 \%$ \\
\hline \multirow[t]{8}{*}{ yalpalmak } & zigzag & 1 & $0.12 \%$ & jagen & chase & 2 & $0.22 \%$ & møffe & & 1 & $0.15 \%$ \\
\hline & & & & pirschen & stalk, approach carefully & 2 & $0.22 \%$ & orme & $\begin{array}{l}\text { move like } \\
\text { worm }\end{array}$ & 1 & $0.15 \%$ \\
\hline & & & & rasen & race, dash, speed & 2 & $0.22 \%$ & piske & dash & 1 & $0.15 \%$ \\
\hline & & & & schaufeln & shovel & 2 & $0.22 \%$ & skøjte & skate & 1 & $0.15 \%$ \\
\hline & & & & schieben & push, shove & 2 & $0.22 \%$ & svæve & hover & 1 & $0.15 \%$ \\
\hline & & & & $\begin{array}{l}\text { spazieren } \\
\text { gehen }\end{array}$ & go for a walk, stroll & 2 & $0.22 \%$ & tage skridt & take steps & 1 & $0.15 \%$ \\
\hline & & & & streifen & prawl, roam & 2 & $0.22 \%$ & & & & \\
\hline & & & & taumeln & sway, stagger & 2 & $0.22 \%$ & & & & \\
\hline
\end{tabular}




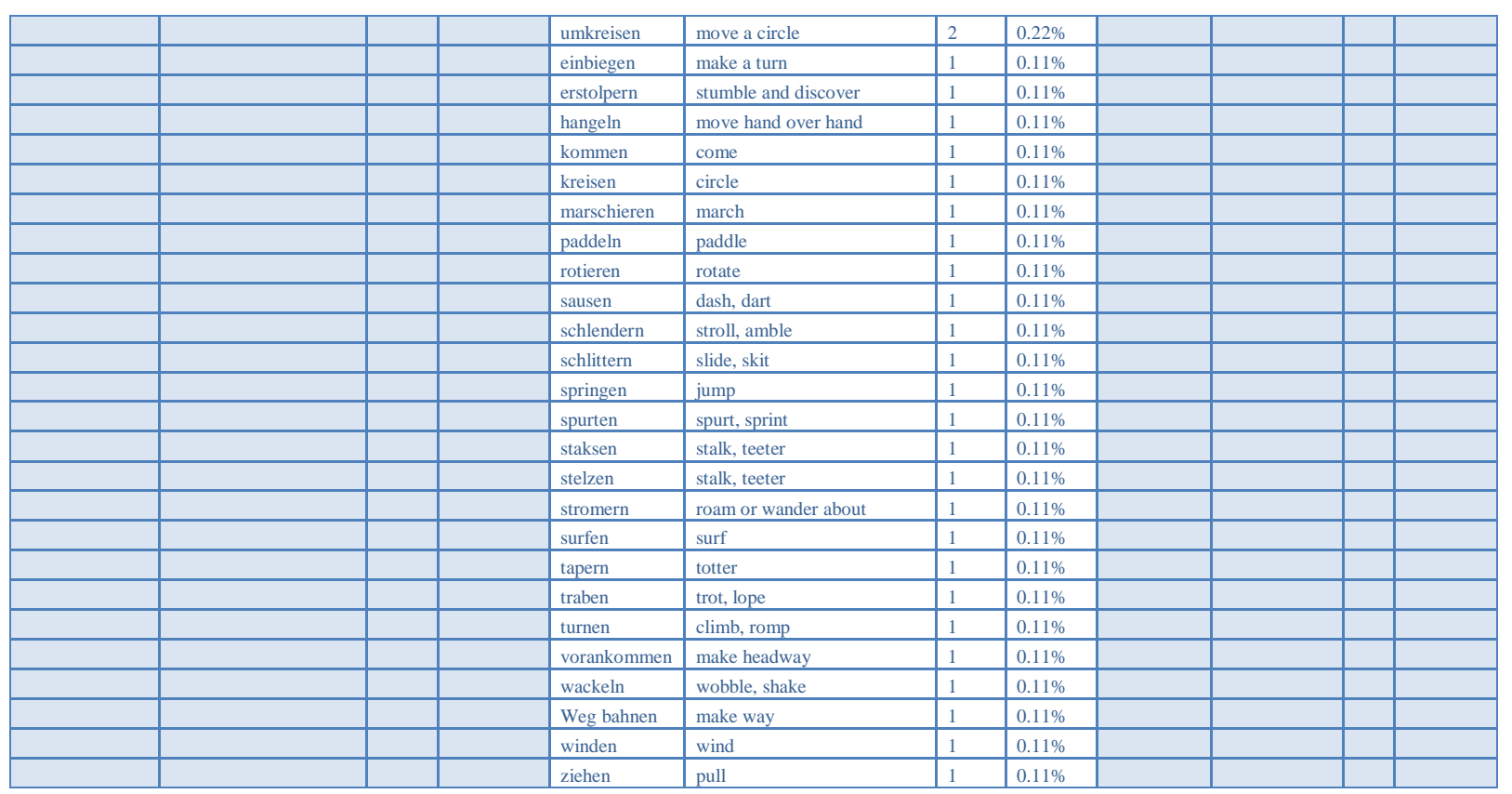

